\title{
The clinical utility of CA125/MUC16 in pancreatic cancer: A consensus of diagnostic, prognostic and predictive updates by the Chinese Study Group for Pancreatic Cancer (CSPAC)
}

\begin{abstract}
LIANG LIU ${ }^{1-3 *}$, JINFENG XIANG $^{1-3 *}$, RUFU CHEN $^{4}$, DELIANG FU ${ }^{5}$, DEFEI HONG ${ }^{6}$, JIHUI HAO $^{7}$, YIXIONG LI ${ }^{8}$, JIANGTAO LI ${ }^{9}$, SHENGPING LI ${ }^{10}$, YIPING MOU ${ }^{11}$, GANG MAI $^{12}$, QUANXING NI ${ }^{1-3}$, LI PENG $^{13}$, RENYI QIN ${ }^{14}$, HONGGANG QIAN ${ }^{15}$, CHENGHAO SHAO ${ }^{16}$, BEI SUN ${ }^{17}$, YONGWEI SUN ${ }^{18}$, MIN TAO ${ }^{19}$, BOLE TIAN ${ }^{20}$, HONGXIA WANG $^{21}$, JIAN WANG ${ }^{18}$, LIWEI WANG ${ }^{22}$, WEI WANG ${ }^{23}$, WEILIN WANG ${ }^{24}$, JUN ZHANG ${ }^{25}$, GANG ZHAO ${ }^{26}$, JUN ZHOU ${ }^{27}$ and XIANJUN YU ${ }^{1-3}$, FOR THE CHINESE STUDY GROUP FOR PANCREATIC CANCER (CSPAC)
\end{abstract}

${ }^{1}$ Department of Pancreatic Surgery, Fudan University Shanghai Cancer Center; ${ }^{2}$ Department of Oncology, Shanghai Medical College, ${ }^{3}$ Pancreatic Cancer Institute, Fudan University, Shanghai;

${ }^{4}$ Department of Pancreaticobiliary Surgery, Sun Yat-sen Memorial Hospital, Sun Yat-sen University, Guangzhou, Guangdong;

${ }^{5}$ Department of Pancreatic Surgery, Pancreatic Disease Institute, Huashan Hospital, Shanghai Medical College,

Fudan University, Shanghai; ${ }^{6}$ Department of Hepatobiliary and Pancreatic Surgery, Zhejiang Provincial People's Hospital, Hangzhou, Zhejiang; ${ }^{7}$ Department of Pancreatic Cancer, Tianjin Medical University Cancer Institute and Hospital, Tianjin;

${ }^{8}$ Department of Pancreatic-Bililary Surgery, Xiangya Hospital, Central South University, Changsha, Hunan;

${ }^{9}$ Department of Surgery, Second Affiliated Hospital of Zhejiang University School of Medicine, Hangzhou;

${ }^{10}$ Department of Hepatobiliary Oncology, Cancer Center, Sun Yat-sen University, Guangzhou, Guangdong;

${ }^{11}$ Department of Gastroenterological and Pancreatic Surgery, Zhejiang Provincial People's Hospital, Hangzhou;

${ }^{12}$ Department of Hepatobiliopancreatic Surgery, The People's Hospital of Deyang, Deyang;

${ }^{13}$ Department of Hepato-Pancreato-Biliary Surgery, The Fourth Hospital of Hebei Medical University, Shijiazhuang;

${ }^{14}$ Department of Biliary-Pancreatic Surgery, Affiliated Tongji Hospital, Tongji Medical College,

Huazhong University of Science and Technology, Wuhan; ${ }^{15}$ Department of Hepato-Pancreato-Biliary Surgery,

Peking University Cancer Hospital and Institute, Beijing; ${ }^{16}$ Department of Pancreatic-Biliary Surgery,

Shanghai Changzheng Hospital, Second Military Medical University, Shanghai; ${ }^{17}$ Department of Pancreatic and Biliary Surgery, The First Affiliated Hospital of Harbin Medical University, Harbin, Heilongjiang;

${ }^{18}$ Department of Biliary-Pancreatic Surgery, Renji Hospital, School of Medicine, Shanghai Jiaotong University,

Shanghai; ${ }^{19}$ Department of Medical Oncology, The First Hospital Affiliated to Soochow University, Suzhou;

${ }^{20}$ Department of Hepato-Biliary-Pancreatic Surgery, West China Hospital, Sichuan University, Chengdu;

${ }^{21}$ Department of Medical Oncology, Renji Hospital, School of Medicine, Shanghai Jiaotong University;

${ }^{22}$ Department of Medical Oncology, Shanghai First People's Hospital; ${ }^{23}$ Department of Surgery, Huadong Hospital,

Fudan University, Shanghai; ${ }^{24}$ Department of Hepatobiliary and Pancreatic Surgery, First Affiliated Hospital,

Zhejiang University School of Medicine, Hangzhou, Zhejiang; ${ }^{25}$ Department of Medical Oncology, Ruijin Hospital,

Shanghai Jiaotong University School of Medicine, Shanghai; ${ }^{26}$ Pancreatic Disease Institute, Union Hospital,

Tongji Medical College, Huazhong University of Science and Technology, Wuhan, Hubei; ${ }^{27}$ Department of Medical Oncology,

Peking University School of Oncolocy, Beijing Institute for Cancer Research, Beijing, P.R. China

Received November 20, 2015; Accepted December 28, 2015

DOI: 10.3892/ijo.2015.3316

Correspondence to: Professor Xianjun Yu, Department of Pancreatic Surgery, Fudan University Shanghai Cancer Center, 270 DongAn Road, Shanghai 200032, P.R. China

E-mail: yuxianjun@fudanpci.org; yuxianjun@fudan.edu.cn

${ }^{*}$ Contributed equally
Abbreviations: PC, pancreatic cancer; TNM, tumor-node-metastasis; $\mathrm{CA}$, cancer antigen; MUC16, mucin 16

Key words: pancreatic cancer, cancer antigen 125, mucin 16, diagnosis, predictive potency, prognosis 
Abstract. The prognosis for pancreatic cancer (PC) is poor; however, the timely and accurate treatment of this disease will significantly improve prognosis. Serum biomarkers involve noninvasive tests that facilitate the early detection of tumors, predict outcomes and assess responses to therapy, so that the patient can be continuously monitored and receive the most appropriate therapy. Studies have reported that cancer antigen (CA)125 [also known as mucin 16 (MUC16)] has functional significance in the tumorigenic, metastatic and drug resistant properties of PC. Our aim was to use this biomarker in the diagnosis, detection of metastasis, prognosis and in the monitoring of the treatment effects of PC. Members of the Chinese Study Group for Pancreatic Cancer (CSPAC) reviewed the literature on CA125/ MUC16 and developed an objective consensus on the clinical utility of CA125/MUC16 for PC. They confirmed the role of CA125/MUC16 in tumorigenesis and the progression of $\mathrm{PC}$, and recommended monitoring CA125/MUC16 levels in all aspects of the diagnosis and treatment of PC, particularly those that involve the monitoring of treatments. In addition, they suggested that the combination of other biomarkers and imaging techniques, together with CA125/MUC16, would improve the accuracy of the clinical decision-making process, thereby facilitating the optimization of treatment strategies. Periodic clinical updates of the use of CA125/MUC16 have been established, which are important for further analyses and comparisons of clinical results from affiliates and countries, particularly as regards the in-depth biological function and clinical translational research of this biomarker.

\section{Introduction}

Pancreatic cancer (PC) remains one of the most lethal malignancies, with an extremely poor prognosis. Individualized treatment based on the accurate evaluation of the disease is urgently required. The traditional method of pre-treatment assessment relies on the tumor-node-metastasis (TNM) staging system, which usually relies on imaging tests. The goal of serum cancer biomarker studies is to develop simple noninvasive tests, with or without the use of other techniques, in order to better characterize tumorigenesis. This may facilitate the early detection of tumors for cancer prognosis, the classification of tumors, and the determination of therapeutic effects, so that the clinician can monitor disease progression, regression and recurrence, in order to help patients receive the most appropriate therapy (1). Cancer antigen (CA)19-9 is the most commonly used biomarker for the diagnosis, prognosis and the therapeutic monitoring of PC. However, the sensitivity and specificity limit its applicability in many cases. CA125/ mucin 16 (MUC16) is a transmembrane mucin, which was originally detected in epithelial cells and mucus layers of the respiratory and gastrointestinal tracts $(2,3)$. The serum levels of CA125 have been widely used in ovarian cancer for diagnosis, the detection of early recurrence, and for the monitoring of the therapeutic effects of treatments (4-6). Recently, studies on the use of CA125/MUC16 in patients with PC treated with resection, radiotherapy or chemotherapy have been published, and may assist in the diagnosis and treatment of this type of cancer (7-9). The Chinese Study Group for Pancreatic Cancer (CSPAC) has provided a consensus on the use of the biomarker CA125/MUC16, its biological significance and its clinical applicability, in order to facilitate the optimization of treatment strategies for PC.

\section{Materials and methods}

The consensus described in this study was conducted by CSPAC. All participating experts are specialists from high volume centers with long-term experience in pancreatic surgery, oncology and scientific research.

Evidence acquisition and synthesis. The inclusion and exclusion criteria for evidence acquisition and synthesis are listed in Table I. A systematic literature search of the PubMed database was performed using the following keywords: 'pancreatic cancer, 'pancreatic adenocarcinoma', 'CA125', 'MUC16', 'diagnosis', 'prognosis', 'predictive factor', 'prognostic factor' and 'survival'. Studies published between the years 2000-2015 were reviewed and selected for further screening analyses and for subsequent consensus studies. The reference lists of the retrieved literature were also cross-searched for additional publications. Only studies published in the English language were included. Overall, 143 reports published between 2000-2015 were retrieved with the consensus of all authors. As the main findings of some studies deviated from the purpose of the consensus, we performed a primary screening based on content browsing, and subsequently exchanged views concerning the primary screening. Finally, 72 reports were selected for further review. due to the paucity of large sample randomized data, studies were finally selected based on the following criteria: the derivation and evolution of relevant concepts, long-term clinical observations and variable and multivariable statistical analyses.

Studies were selected based mainly on 4 categories: diagnostic significance, predictive significance, prognostic significance and therapeutic monitoring significance. A detailed description of the final selected reports (associated with clinical application rather than pure basic research in PC) is presented in Table II. Due to the lack of studies concerning CA125/MUC16 and its use in PC, only a limited amount of data were available. However, several single-institutional and multiinstitutional studies were published that provided meaningful information on diagnostic, prognostic and predictive updates of patients with PC. Several promising combined biomarkers were also evaluated; however, further studies are warranted in order to accurately determine their clinical significance.

All CSPAC participants reviewed all the relevant reports and contributed to the consensus. Draft versions were circulated among the participants over a period of 3 months, and all comments and suggestions were considered before all the CSPAC participants agreed to a final consensus statement.

\section{Results}

Molecular characteristics and functional significance of CA125/MUC16. CA125 is a repeating peptide epitope of the mucin MUC16, which is a large, complex glycoprotein (10). There are a number of repeats in the tandem repeat region (18-60 amino acids) that result in various isoforms of MUC16 and confer functional heterogeneity (11). MUC16 undergoes continuous glycosylation and deglycosylation throughout its presence in bodily fluids, leading to significant heterogeneity in both size and 
Table I. Inclusion and exclusion criteria for literature review.

Criteria

Inclusion criteria

Including keywords in all fields

Writing language

Publication date

Highlights and contents conform with the purpose of consensus

Exclusion criteria

Highlights and contents deviate from the purpose of consensus

Disagreement and controversy

Sample capacity
'Pancreatic cancer', 'pancreatic adenocarcinoma', 'CA125', 'MUC16', 'diagnosis', 'prognosis', 'predictive factor', 'prognostic factor' and 'survival'

English

From 2000 to 2015

Derivation and evolution of relevant concepts; long-term clinical observation; variable and multivariable statistical analyses

Fail to pass the cross-talk between experts or more than half exchanged views are inconsistent at the time of primary screening Case report or sample size is $<50$ charge (12). In addition, the glycosylated region potentially interacts with other glycosylated proteins to activate various signaling pathways (13). Furthermore, the levels of CA125/MUC16 show a correlation with immunological responses, proliferation and migration pathways in both physiological and pathological conditions (14,15). Under normal biological conditions, MUC16 is expressed in the epithelial lining, where its primary functions are to provide hydration and lubrication (16). Studies have analyzed the specific role of CA125/MUC16 in various types of cancer (2,17-21). In breast cancer cells, MUC16 has been shown to interact with Janus kinase 2 (JAK2) and phosphorylates signal transducer and activator of transcription 3 (STAT3), eventually increasing the transcription of cyclin D1 for cell proliferation (18). CA125/MUC16 can affect the formation of the glycocalyx by interacting with galectin 1 and 3 in normal epithelial cells. However, in cancer cells, this enhanced interaction facilitates cancer progression (22). The MUC16-mesothelin interaction in ovarian cancer and PC cells leads to the upregulation of matrix metalloproteinase (MMP)-7 expression by increasing the phosphorylation of p38 mitogen-activated protein kinase (MAPK), activating cell invasion and migration (23). These studies have demonstrated the context-dependent function of CA125/MUC16 in organ development, cancer cell proliferation, metastasis, the regulation of immune responses and in anticancer therapeutic effects. From these data, tumors are now classified based on their molecular phenotype and not solely on their histological attributes. For example, the overexpression of CA125 on the cell surface has already been identified in heterogeneous malignant diseases, such as ovarian cancer, lung cancer, uterine cancer, gastrointestinal cancer and PC, and has become an important marker for tumor management (23-26).

The clinical applicability of CA125/MUC16 assays has resulted from basic, translational and clinical studies for over three decades. The serum levels of CA125 are commonly monitored in patients with ovarian cancer, and an increase over an individualized baseline concentration is a prognostic indicator of cancer recurrence (6). Although CA125 has often been used for the diagnosis of ovarian cancer, the measurement of the levels of CA125/MUC16 is also valuable in other types of cancer, and numerous large-scale clinical trials have been conducted or are underway to determine the possible use of CA125/MUC16 as a biomarker in many other solid cancers $(7,19-21,27)$.

Use of CA125/MUC16 for the diagnosis of PC. The clinical stage of the disease at diagnosis often determines the prognosis and survival rate of a patient with PC (28). The early symptoms of PC are not always obvious on imaging (ultrasound or computed tomography), and when patients present with weight loss, jaundice, abdominal pain and other symptoms, they are usually already in the advanced stages of PC (29). However, the detection of different tumor markers, such as CA125, with appropriate sensitivity or specificity, may facilitate early diagnosis and provide a meaningful parameter in gastrointestinal tumors $(27,30,31)$.

The conventional view is that tumor biomarkers, such as CA19-9 and CA125 are upregulated late in the course of PC development $(32,33)$. However, recent studies have reported that CA19-9 and CA125 can be detected up to 1-2 years prior to diagnosis, and that the combination of CA19-9 and CA125 can improve the diagnostic sensitivity, as elevated CA125 levels are not only observed in CA19-9-positive cases, but also in approximately $20 \%$ of CA19-9-negative cases. Moreover, their preclinical levels (the cut-off value of CA125 is $30 \mathrm{U} / \mathrm{ml}$, Table II) also correlate with prognosis, which demonstrate its value for the preclinical evaluation of PC (34). CA19-9 is a classical serum biomarker commonly used in pancreatic ductal adenocarcinoma (PDAC). Its sensitivity and specificity for diagnosis are 79-81 and 82-90\%, respectively (32). However, a common problem involves false-positive results found in benign pancreaticobiliary diseases, such as pancreatitis, obstructive jaundice and cholangitis $(33,35)$. In these patients, serum levels of CA125 provide a valuable contribution in the diagnosis of differentiating malignant and benign pancreatic diseases (33). The sensitivity and specificity for serum CA125 are 41.7-70.3 and $75.1-96.3 \%$ (Table II), respectively $(34,36)$. However, CA125 also has a rare diagnostic value in cases where CA19-9 is not elevated, particularly in those patients who are negative for Lewis antigen (34). The most commonly used cut-off value of CA125 is approximately 30-35 U/ml (5,37); however, other studies have reported that a lower level of CA125 may also have significance for diagnosis $(7,9,34,38)$. 
Table II. Summary of the available literature on the relevant clinical significance of serum levels of CA125 in pancreatic cancer.

\begin{tabular}{|c|c|c|c|c|c|c|c|c|c|c|}
\hline \multirow[b]{2}{*}{ Classification } & \multirow[b]{2}{*}{$\begin{array}{l}\text { Authors/ } \\
\text { (Ref.) }\end{array}$} & \multirow[b]{2}{*}{ Year } & \multirow[b]{2}{*}{$\begin{array}{l}\text { Country/ } \\
\text { region }\end{array}$} & \multirow[b]{2}{*}{$\begin{array}{l}\text { Sample } \\
\text { size }\end{array}$} & \multicolumn{2}{|c|}{ CA19-9 } & \multicolumn{2}{|c|}{ CA125 } & \multicolumn{2}{|c|}{ CA19-9 + CA125 } \\
\hline & & & & & $\begin{array}{c}\text { Sensitivity } \\
(\%)\end{array}$ & $\begin{array}{c}\text { Specificity } \\
(\%)\end{array}$ & $\begin{array}{c}\text { Sensitivity } \\
(\%)\end{array}$ & $\begin{array}{c}\text { Specificity } \\
(\%)\end{array}$ & $\begin{array}{c}\text { Sensitivity } \\
(\%)\end{array}$ & $\begin{array}{c}\text { Specificity } \\
(\%)\end{array}$ \\
\hline \multirow[t]{8}{*}{$\begin{array}{l}\text { Diagnostic } \\
\text { significance }\end{array}$} & $\begin{array}{l}\text { Chan et al } \\
\text { (36) }\end{array}$ & 2014 & $\begin{array}{l}\text { Pittsburgh, } \\
\text { PA, USA }\end{array}$ & 400 & 77.5 & 83.1 & 70.3 & 75.1 & 81.1 & 87.7 \\
\hline & $\begin{array}{l}\text { Wang et al } \\
\text { (79) }\end{array}$ & 2013 & $\begin{array}{l}\text { Beijing, } \\
\text { China }\end{array}$ & 145 & 73.3 & 85.7 & 30.7 & 88.6 & - & - \\
\hline & $\begin{array}{l}\text { Liu et al } \\
\quad(42)\end{array}$ & 2014 & $\begin{array}{l}\text { Shandong, } \\
\text { China }\end{array}$ & 705 & - & - & - & - & - & - \\
\hline & $\begin{array}{c}\text { O'Brien et al } \\
\text { (34) }\end{array}$ & 2015 & UK & 565 & $75.0 / 37.5^{\mathrm{a}}$ & $92.6 / 96.2^{a}$ & $41.7 / 12.5^{\mathrm{a}}$ & $96.3 / 96.2^{\mathrm{a}}$ & $83.3 / 43.8^{\mathrm{a}}$ & $88.9 / 92.3^{\mathrm{a}}$ \\
\hline & $\begin{array}{c}\text { Yang et al } \\
(80)\end{array}$ & 2014 & $\begin{array}{l}\text { Beijing, } \\
\text { China }\end{array}$ & 913 & - & - & - & - & - & - \\
\hline & $\begin{array}{l}\text { Nolen et al } \\
\quad(81)\end{array}$ & 2014 & $\begin{array}{l}\text { Pittsburgh, } \\
\text { PA, USA }\end{array}$ & 675 & $21.8^{\mathrm{b}}$ & - & $6.67^{\mathrm{b}}$ & - & - & - \\
\hline & $\begin{array}{c}\text { Duraker et al } \\
\text { (56) }\end{array}$ & 2007 & Turkey & 181 & 81.3 & 75.9 & 56.9 & 77.6 & - & - \\
\hline & $\begin{array}{c}\text { Cwik et al } \\
\text { (34) }\end{array}$ & 2006 & Poland & 110 & 80.8 & 89.1 & 60.8 & 83.3 & 87.8 & 77.8 \\
\hline \multirow[t]{2}{*}{$\begin{array}{l}\text { Predictive } \\
\text { significance }\end{array}$} & $\begin{array}{l}\text { Okada et al } \\
\text { (9) }\end{array}$ & 2014 & Japan & 200 & 40.8 & 58.5 & 69.1 & 71.3 & - & - \\
\hline & $\begin{array}{l}\text { Luo et al } \\
\quad(37)\end{array}$ & 2013 & $\begin{array}{l}\text { Shanghai, } \\
\text { China }\end{array}$ & 212 & 63.24 & 71.05 & 78.68 & 71.05 & - & - \\
\hline \multirow[t]{4}{*}{$\begin{array}{l}\text { Prognostic } \\
\text { significance }\end{array}$} & $\begin{array}{l}\text { Chen et al } \\
\quad(52)\end{array}$ & 2015 & $\begin{array}{l}\text { Shanghai } \\
\text { China }\end{array}$ & 211 & - & - & - & - & - & - \\
\hline & $\begin{array}{l}\text { Chang et al } \\
\quad(82\end{array}$ & 2009 & USA & 95 & 80.0 & - & - & - & - & - \\
\hline & $\begin{array}{c}\text { Chen et al } \\
\quad(8)\end{array}$ & 2014 & $\begin{array}{l}\text { Henan, } \\
\text { China }\end{array}$ & 62 & 93.5 & 93.5 & 74.2 & 100 & - & - \\
\hline & $\begin{array}{l}\text { Liu et al } \\
\quad(7)\end{array}$ & 2015 & $\begin{array}{l}\text { Shanghai, } \\
\text { China }\end{array}$ & 709 & $\mathrm{c}$ & $\mathrm{c}$ & $\mathrm{c}$ & $\mathrm{c}$ & $\mathrm{c}$ & $\mathrm{c}$ \\
\hline \multirow[t]{2}{*}{$\begin{array}{l}\text { Treatment } \\
\text { monitoring }\end{array}$} & $\begin{array}{l}\text { Chen et al } \\
\quad \text { (52) }\end{array}$ & 2015 & $\begin{array}{l}\text { Shanghai, } \\
\text { China }\end{array}$ & 211 & - & - & - & - & - & - \\
\hline & $\begin{array}{l}\text { Shi et al } \\
\quad(48)\end{array}$ & 2015 & $\begin{array}{l}\text { Shanghai, } \\
\text { China }\end{array}$ & 60 & - & - & - & - & - & - \\
\hline
\end{tabular}

The comparison results in these studies are all between pancreatic ductal adenocarcinoma (PDAC) and benign pancreatic diseases. ${ }^{\mathrm{T}}$ The numbers before and after the separatrix, respectively refer to the sensitivity or specificity in $0-0.5$ and $0.5-1$ years prior to diagnosis (CA19-9>37 U/ml; CA125>30 U/ml). ${ }^{\mathrm{b}}$ Sensitivity at $95 \%$ specificity. ${ }^{\circ}$ These studies in particular perfomred a more extensive subgroup analysis to find that the panel of tumor markers $\left(\mathrm{CEA}^{+} /\right.$ $\mathrm{CA} 125^{+} / \mathrm{CA} 19-9 \geq 1,000 \mathrm{U} / \mathrm{ml}$ ) could independently predict the non-decrease in CA19-9 levels post-operatively and were closely associated with a poor surgical outcome.

Distant metastasis at the time of diagnosis is a major reason for a poor prognosis, and is considered the major obstacle to the effective use of surgery as a treatment option. Surgeons sometimes encounter distant metastases intraoperatively, including tiny liver metastases or a small amount of peritoneal metastases, which are difficult to detect pre-operatively using recently developed imaging techniques $(39,40)$. The traditional strategy uses pre-operative chemotherapy or chemoradiotherapy after the identification of patients who are unlikely to benefit from resection. If metastasis occurs during treatment, it is a time-consuming process, which may delay an optimal surgical outcome $(41,42)$. In addition, the follow-up period is sometimes inadequate to treat metastasis effectively. Studies have reported that the measurement of a series of tumor markers [CA19-9, CA125, carcinoembryonic antigen (CEA), alpha-fetoprotein (AFP), CA242, CA72-4, CA50, CA15-3, and the beta-subunit of human chorionic gonadotropin (hCG- $\beta$ )] improves the early diagnosis of cancer $(36,43)$. CA125/MUC16 is aberrantly expressed in various types of cancer, and it can promote proliferation, migration and metastasis by facilitating metastatic and invasive gene transcription $(23,44,45)$. Increasing preclinical studies have reported that CA125 levels are closely related with distant metastasis $(39,46)$. However, due to its limited specificity, the measurement of a single tumor marker is usually not sufficient to accurately diagnose cancer (31). 
Consensus statement. We recommend the use of CA125 for diagnosis (including metastasis and differential diagnosis between benign and malignant diseases), particularlyy in cases which are CA19-9-negative. Simultaneous assessments, including various biomarkers, oncogenomic analyses and functional imaging tests, such as positron emission tomography with 2-deoxy-2-[fluorine-18] fluoro-D-glucose integrated with computed tomography $\left({ }^{18} \mathrm{FDG} \mathrm{PET} / \mathrm{CT}\right)$ are important for the accurate diagnosis of PC (47-50).

Special applications during jaundice and effusion. Tumor marker levels may show false-positives in some benign diseases or complications, which can lead to the overestimation or to confusion regarding the actual condition of the disease. Hepatobiliary disease and renal failure are commonly associated with false-positive results $(43,51)$. Compared to patients with benign jaundice, patients with malignant jaundice have higher levels of CA19-9, which do not significantly decrease even after drainage (52). CA19-9 has a better sensitivity; however, CA125 and CEA have higher specificities than CA19-9 for the diagnosis of patients with malignant tumors (52). Nonetheless, the use of serum CA19-9 levels alone is not always reliable in patients with hyperbilirubinemia and the CA19-9 non-secreter phenotype. CA19-9 levels can be affected by hyperbilirubinemia, which induces an increase in serum levels. Furthermore, we recently found that there is little or no correlation between CA125 and serum bilirubin levels (less affected by relieving jaundice) (53). Thus, CA125, but not CA19-9, may be more stable, and could more accurately predict the prognosis of patients with PDAC with hyperbilirubinemia (53). Certain studies have also suggested that serum CA125 levels vary in different types of effusions, and that the levels are closely related to peritoneal metastasis $(38,54)$.

Consensus statement. We recommend using CA125 levels to assist in clinical diagnosis and preclinical prediction as a supplement to CA19-9 levels, particularly in some special conditions, such as hyperbilirubinemia. A second or third cut-off for serum CA125 levels (concentrations of more or less than the commonly used value of $35 \mathrm{U} / \mathrm{ml}$ ) should be considered if necessary (55-57).

\section{Predictive and prognostic use of serum CA125 in pre-treatment evaluation}

Predicting surgical outcomes prior to surgery and use as a guide for pre-operative or post-operative comprehensive treatment strategies. Previous studies have reported that CA19-9 can assist in assessing the resectability of PC by using three-dimensional computed tomography (CT) reconstruction (58-61). We previously reported that CA125 was superior to CA19-9 in predicting the resectability of PC (38). Aberrantly high levels of CA125 may indicate unresectable PC, even for patients diagnosed by $\mathrm{CT}$ as being resectable. Moreover, in the assessment of the therapeutic effects to the patient after surgery, we found that a subset of patients with post-operatively decreased CA19-9 levels would have a survival advantage. We also identified a series of tumor markers $\left(\mathrm{CEA}^{+} / \mathrm{CA} 125^{+} /\right.$ CA19-9 $\geq 1,000 \mathrm{U} / \mathrm{ml}$ ) which could independently predict the post-operative maintenance of elevated CA19-9 levels, and were closely associated with poor surgical outcomes, in order to select appropriate therapies for patients with PC before treatment (7). The treatment of PC is increasingly multimodal; therefore patients receive chemotherapy or chemoradiation pre-operatively or post-operatively in order to achieve longterm benefits $(29,62)$. Current guidelines support a neoadjuvant strategy for patients with locally advanced and borderline resectable disease (63). However, the necessity of these treatments is still controversial for PC due to the complexity and presence of a possibly latent preo-perative metastatic disease, making it difficult to judge whether a patient would benefit from a particular treatment, particularly for borderline resectable patients (64). For patients with resectable and borderline resectable PC, recent studies have evaluated the necessity and efficacy of neoadjuvant therapy based on pre-treatment assessments $(65,66)$. Serum biomarkers (CA19-9, mesothelin, and CA125) have proven to be effectively able of identifying patients who harbor micrometastatic disease. These patients should therefore receive neoadjuvant chemotherapy, thus sparing them from the potential morbidities associated with unnecessary radiation or surgery $(23,67)$.

Predictive prognosis indicating post-operative recurrence and metastasis. The pre-operative CA125 level is a useful predictive biomarker for curative resection, and is a prognostic biomarker for recurrence in various types of cancer (epithelial ovarian carcinoma, breast cancer and lung cancer) $(4,68,69)$. A recent study indicated that CA125 is an independent prognostic factor for gastric cancers, and an independent predictor of peritoneal metastasis (27). Patients with elevated serum CA125 levels, as compared to those with normal serum CA125 levels, have significantly higher incidences of peritoneal metastasis (39). Moreover, elevated CA125 levels also indicate a lower 5-year overall survival rate in patients with gastrointestinal cancer (39,70). In our previous study, we also found that CA125 expression was much higher in metastatic lesions and was related with the metastasis-associated burden. When ${ }^{18}$ F-FDG PET/CT was not available, we used CA19-9 and CA125 levels to establish equations for metabolic tumor volume (MTV) and total lesion glycolysis (TLG) based on their functional properties reflecting metabolic tumor burden. Our results suggested that the metabolic tumor burden estimated by serum tumor biomarkers may be suitable for monitoring the response to treatment and the progression of PC (49). Recently, we reported that pre-operative CA125 levels can predict post-operative early recurrence (Liu et al, unpublished data). In addition, another recent study revealed the co-expression of CA125 and mesothelin in PC, which was associated with a poor prognosis due to the related initiation of intracavitary tumor metastasis (23). Not only CA125 alone, but other serum tumor biomarkers such as CA242, CA19-9 and CEA, when used as prognostic tools, may also be of great clinical value for the efficacy and prognosis of specific treatments for patients with PC, with the possibility of recurrence and metastasis (8).

Consensus statement. We recommend the pre-operative detection of CA125 levels in serum. Patients with high pre-operative CA125 levels need to be alerted to the presence of microsystemic metastases. Moreover, patients with high pre-operative CA125 levels also need close follow-up after surgery and active post-operative adjuvant treatment to prevent possible future 
recurrence and metastasis. For those patients with significantly abnormal levels of CA125 prior to surgery, particularly those with $\mathrm{CEA}^{+} / \mathrm{CA} 125^{+} / \mathrm{CA} 19-9 \geq 1,000 \mathrm{U} / \mathrm{ml}$, a multidisciplinary comprehensive treatment is recommended and an active neoadjuvant therapy should be performed when microsystemic metastases is highly suspected. However, this strategy requires additional data from further evidence-based medical studies, so additional prospective clinical trials are urgently required.

The value of monitoring therapeutic effects during follow-up. The serum CA125 level is routinely used in ovarian cancer to monitor the effectiveness of therapy $(6,71)$. In addition, it is widely used during follow-up to identify a subgroup of patients with dormant recurrence (46). A previous study demonstrated an association between the dynamic changes in CA125 levels, tumor size reduction, the remission of clinical symptoms and chemotherapeutic effects (6). Additional studies have indicated that the elevation in the serum levels of CA125 correlate with cancer progression and treatment effects $(72,73)$. Our team previously showed a better efficacy for CA125 compared with CA19-9 levels in determining the resectability of PC (38). Moreover, we recently demonstrated that CA125 was closely associated with the metastatic tumor burden and disease progression in patients with PC (Liu et al, unpublished data). Measuring the serum CA125 level may provide a useful index for determining the course of PC and for monitoring the therapeutic effects.

Consensus statement. We recommend that CA125 monitoring should be used for patients during follow-up to monitor the disease course and therapeutic effects, to assist in evaluating the curative effects, and to adjust the treatment strategy.

The value of combined applications with other biomarkers and metabolic imaging. Due to limited sensitivity and specificity, the measurement of a single tumor biomarker is usually not sufficient to evaluate tumor development $(30,74)$. Certain studies have indicated that the serum levels of individual biomarkers, such as CA125, CEA, CA19-9, and CA242 are not associated with tumor size (8). However, patients with high expression levels of these markers presented with late-stage disease, which demonstrated that a comprehensive assessment of various biomarkers, to provide more biological information, was necessary $(8,31,43)$. In previous studies, the multi-analysis of different biomarkers [CA19-9, neuron specific enolase (NSE), CEA, CA242, CA125, circulating tumor cells and ctDNA] was more useful in the diagnosis and prognosis of $\mathrm{PC}$, and was superior to that of any single biomarker (75,76). Currently, PET has been widely used in clinical practice to improve diagnosis and regular reexamination by detecting metastasis, even when it is slight and asymptomatic $(77,78)$. We recently proposed a promising method for the pre-operative prediction of the prognosis of patients with PC using the combination of ${ }^{18} \mathrm{~F}$-FDG PET/CT and serum CA19-9 levels (47). Due to the important role of CA125 for the diagnosis, prognosis and course monitoring of $\mathrm{PC}$, the combination of serum CA125 and metabolic imaging with ${ }^{18} \mathrm{~F}-\mathrm{FDG}$ PET/ CT may be effective, but requires further validation.

Consensus statement. We recommend that the combination of CA125 and other serum/tissue biomarkers, or similar combined applications, such as CA19-9 levels along with ${ }^{18}$ FDG PET/CT are important for the diagnosis, treatment and surveillance of patients with $\mathrm{PC}$ at follow-up.

\section{Discussion}

All recommendations were created based on the literature reviews of basic and clinical studies by all authors of this consensus study. The retrieved results originated from the PubMed database, and were all reviewed in detail. Due to the limited number of contributors, a possible bias may exist. In addition, it is noteworthy that although the authors selected the studies to be included based on the criteria mentioned herein, a selection bias may have occurred due to the lack of reported randomized trials. However, previous and ongoing studies have indicated that there is a novel hypothesis concerning the clinical use of CA125/MUC16 levels in many aspects of PC management. This study evaluated these common results and extracted recommendations for future studies.

Within the present CSPAC consensus statement, CA125/ MUC16 has been verified as useful for diagnosis, the detection of metastasis, predicting prognosis and monitoring the therapeutic effects of PC treatments, which may be helpful for selecting the appropriate therapy and monitoring disease progression, regression and recurrence. In particular, the data support the hypothesis that CA125/MUC16 plays an oncogenic and metastasis-predictive role in the progression of $\mathrm{PC}$, and correlates with the metastatic tumor burden. Although the most commonly used cut-off value of CA125 is $30-35 \mathrm{U} / \mathrm{ml}(5,37)$, data indicate that a lower level of CA125 may have a significant diagnostic or predictive value for PC $(34,38)$. In some cases, a second or third cut-off value (concentrations less or more than $35 \mathrm{U} / \mathrm{ml} \mathrm{CA125)}$ is recommended (55-57). However, evaluations using a single biomarker are less effective; therefore, the use of CA125/MUC16 levels may complement the use of CA19-9 levels and imaging tests, such as PET/CT. The importance of CA125/MUC16 in PC suggests the need for additional studies on biological functions and clinical translation. As shown in our studies, the combination of various serological biomarkers $\left(\mathrm{CA}^{2} 25^{+} / \mathrm{CEA}^{+} / \mathrm{CA} 19-9 \geq 1,000 \mathrm{U} / \mathrm{ml}\right)$ and metabolic imaging may be more useful in the evaluation of patients with PDAC and ultimately may promote the development of precise individualized treatment options $(7,47)$.

\section{Acknowledgements}

We would like to thank Huaxiang $\mathrm{Xu}$, WenQuan Wang, Chuantao Wu, Zihao Qi, Jin Xu, Chen Liu, Jiang Long, Bo Zhang, Huanyu Xia and Guopei Luo for their preliminary work for the consensus. We would also like to thank Bioscience Writers, LLC (8418 Bluegate St., Houston TX 77025, USA) for their assistance in editing this manuscript. This study was supported by the National Natural Science Foundation of China (81402397, 81472670, 81402398 and 81172005), the National Natural Science Foundation of Shanghai (14ZR1407600), the 'Yang-Fan' Plan for Young Scientists of Shanghai (14YF1401100), Ph.D. Programs Foundation of Ministry of Education of China (20110071120096).

\section{References}

1. Dalton WS and Friend SH: Cancer biomarkers - an invitation to the table. Science 312: 1165-1168, 2006. 
2. Streppel MM, Vincent A, Mukherjee R, Campbell NR, Chen SH, Konstantopoulos K, Goggins MG, Van Seuningen I, Maitra A and Montgomery EA: Mucin 16 (cancer antigen 125) expression in human tissues and cell lines and correlation with clinical outcome in adenocarcinomas of the pancreas, esophagus, stomach, and colon. Hum Pathol 43: 1755-1763, 2012.

3. Bafna S, Kaur S and Batra SK: Membrane-bound mucins: The mechanistic basis for alterations in the growth and survival of cancer cells. Oncogene 29: 2893-2904, 2010.

4. Bocheva Y, Bochev P and Ivanov S: Ca-125 in diagnosis and monitoring of patients with ovarian cancer. Akush Ginekol (Sofiia) 54: 11-17, 2015 (In Bulgarian)

5. Gasiorowska E, Michalak M, Warchoł W,Lemańska A, Jasiński P, Spaczyński M and Nowak-Markwitz E: Clinical application of HE4 and CA125 in ovarian cancer type I and type II detection and differential diagnosis. Ginekol Pol 86: 88-93, 2015.

6. Gadducci A, Menichetti A, Guiggi I, Notarnicola M and Cosio S Correlation between CA125 levels after sixth cycle of chemotherapy and clinical outcome in advanced ovarian carcinoma Anticancer Res 35: 1099-1104, 2015.

7. Liu L, Xu H, Wang W, Wu C, Chen Y, Yang J, Cen P, Xu J, Liu C, Long J, et al: A preoperative serum signature of $\mathrm{CEA}^{+} / \mathrm{CA}^{2} 25^{+}$ CA19-9 $\geq 1000 \mathrm{U} / \mathrm{ml}$ indicates poor outcome to pancreatectomy for pancreatic cancer. Int J Cancer 136: 2216-2227, 2015.

8. Chen Y, Gao SG, Chen JM, Wang GP, Wang ZF, Zhou B, Jin CH Yang YT and Feng XS: Serum CA242, CA199, CA125, CEA, and TSGF are biomarkers for the efficacy and prognosis of cryoablation in pancreatic cancer patients. Cell Biochem Biophys: Dec 9, 2014 (Epub ahead of print)

9. Okada K, Kawai M, Tani M, Hirono S, Miyazawa M, Shimizu A, Kitahata Y and Yamaue H: Predicting factors for unresectability in patients with pancreatic ductal adenocarcinoma. J Hepatobiliary Pancreat Sci 21: 648-653, 2014.

10. Bast RC Jr, Badgwell D, Lu Z, Marquez R, Rosen D, Liu J, Baggerly KA, Atkinson EN, Skates S, Zhang Z, et al: New tumor markers: CA125 and beyond. Int J Gynecol Cancer 15 (Suppl 3): 274-281, 2005

11. Bressan A, Bozzo F, Maggi CA and Binaschi M: OC125, M11 and OV197 epitopes are not uniformly distributed in the tandemrepeat region of CA125 and require the entire SEA domain. Dis Markers 34: 257-267, 2013.

12. Felder M, Kapur A, Gonzalez-Bosquet J, Horibata S, Heintz J, Albrecht R, Fass L, Kaur J, Hu K, Shojaei H, et al: MUC16 (CA125): Tumor biomarker to cancer therapy, a work in progress. Mol Cancer 13: 129, 2014.

13. Govindarajan B and Gipson IK: Membrane-tethered mucins have multiple functions on the ocular surface. Exp Eye Res 90 655-663, 2010.

14. Tyler C, Kapur A, Felder M, Belisle JA, Trautman C, Gubbels JA Connor JP and Patankar MS: The mucin MUC16 (CA125) binds to NK cells and monocytes from peripheral blood of women with healthy pregnancy and preeclampsia. Am J Reprod Immunol 68 28-37, 2012 .

15. Rachagani S, Torres MP, Kumar S, Haridas D, Baine M, Macha MA, Kaur S, Ponnusamy MP, Dey P, Seshacharyulu P, et al: Mucin (Muc) expression during pancreatic cancer progression in spontaneous mouse model: Potential implications for diagnosis and therapy. J Hematol Oncol 5: 68, 2012.

16. Gipson IK and Argüeso P: Role of mucins in the function of the corneal and conjunctival epithelia. Int Rev Cytol 231: 1-49, 2003.

17. Haridas D, Chakraborty S, Ponnusamy MP, Lakshmanan I, Rachagani S, Cruz E, Kumar S, Das S, Lele SM, Anderson JM, et al: Pathobiological implications of MUC16 expression in pancreatic cancer. PLoS One 6: e26839, 2011.

18. Lakshmanan I, Ponnusamy MP, Das S, Chakraborty S, Haridas D, Mukhopadhyay P, Lele SM and Batra SK: MUC16 induced rapid G2/M transition via interactions with JAK2 for increased proliferation and anti-apoptosis in breast cancer cells Oncogene 31: 805-817, 2012

19. Cedrés S, Nuñez I, Longo M, Martinez P, Checa E, Torrejón D and Felip E: Serum tumor markers CEA, CYFRA21-1, and CA-125 are associated with worse prognosis in advanced nonsmall-cell lung cancer (NSCLC). Clin Lung Cancer 12: 172-179, 2011.

20. Higashi M, Yamada N, Yokoyama S, Kitamoto S, Tabata K, Koriyama C, Batra SK and Yonezawa S: Pathobiological implications of MUC16/CA125 expression in intrahepatic cholangiocarcinoma-mass forming type. Pathobiology 79: 101-106, 2012 .
21. Togami S, Nomoto M, Higashi M, Goto M, Yonezawa S, Tsuji T, Batra SK and Douchi T: Expression of mucin antigens (MUC1 and MUC16) as a prognostic factor for mucinous adenocarcinoma of the uterine cervix. J Obstet Gynaecol Res 36: 588-597, 2010.

22. Argüeso P, Guzman-Aranguez A, Mantelli F, Cao Z, Ricciuto J and Panjwani N: Association of cell surface mucins with galectin-3 contributes to the ocular surface epithelial barrier. J Biol Chem 284: 23037-23045, 2009.

23. Chen SH, Hung WC, Wang P, Paul C and Konstantopoulos K: Mesothelin binding to CA125/MUC16 promotes pancreatic cancer cell motility and invasion via MMP-7 activation. Sci Rep 3: 1870, 2013.

24. Giannakouros P, Comamala M, Matte I, Rancourt C and Piché A: MUC16 mucin (CA125) regulates the formation of multicellular aggregates by altering $\beta$-catenin signaling. Am J Cancer Res 5: 219-230, 2015.

25. Ricardo S, Marcos-Silva L, Pereira D, Pinto R, Almeida R, Söderberg O, Mandel U, Clausen H, Felix A, Lunet N, et al: Detection of glyco-mucin profiles improves specificity of MUC16 and MUC1 biomarkers in ovarian serous tumours. Mol Oncol 9: 503-512, 2015.

26. Kufe DW: Mucins in cancer: Function, prognosis and therapy. Nat Rev Cancer 9: 874-885, 2009.

27. Kim DH, Yun HY, Ryu DH, Han HS, Han JH, Yoon SM and Youn SJ: Preoperative CA 125 is significant indicator of curative resection in gastric cancer patients. World J Gastroenterol 21: 1216-1221, 2015

28. Paulson AS, Tran Cao HS, Tempero MA and Lowy AM: Therapeutic advances in pancreatic cancer. Gastroenterology 144: 1316-1326, 2013

29. Vincent A, Herman J, Schulick R, Hruban RH and Goggins M: Pancreatic cancer. Lancet 378: 607-620, 2011.

30. Shimada H, Noie T, Ohashi M, Oba K and Takahashi Y: Clinical significance of serum tumor markers for gastric cancer: A systematic review of literature by the Task Force of the Japanese Gastric Cancer Association. Gastric Cancer 17: 26-33, 2014.

31. Li Y, Li DJ, Chen J, Liu W, Li JW, Jiang P, Zhao X, Guo F, Li XW and Wang SG: Application of Joint Detection of AFP, CA19-9, CA125 and CEA in Identification and Diagnosis of Cholangiocarcinoma. Asian Pac J Cancer Prev 16: 3451-3455, 2015.

32. Ballehaninna UK and Chamberlain RS: The clinical utility of serum CA 19-9 in the diagnosis, prognosis and management of pancreatic adenocarcinoma: An evidence based appraisal. J Gastrointest Oncol 3: 105-119, 2012

33. Cwik G, Wallner G, Skoczylas T, Ciechanski A and Zinkiewicz K: Cancer antigens 19-9 and 125 in the differential diagnosis of pancreatic mass lesions. Arch Surg 141: 968-973, discussion 974, 2006.

34. O'Brien DP, Sandanayake NS, Jenkinson C, Gentry-Maharaj A, Apostolidou S, Fourkala EO, Camuzeaux S, Blyuss O, Gunu R, Dawnay A, et al: Serum CA19-9 is significantly upregulated up to 2 years before diagnosis with pancreatic cancer: Implications for early disease detection. Clin Cancer Res 21: 622-631, 2015.

35. Steinberg W: The clinical utility of the CA 19-9 tumor-associated antigen. Am J Gastroenterol 85: 350-355, 1990.

36. Chan A, Prassas I, Dimitromanolakis A, Brand RE, Serra S, Diamandis EP and Blasutig IM: Validation of biomarkers that complement CA19.9 in detecting early pancreatic cancer. Clin Cancer Res 20: 5787-5795, 2014.

37. Menczer J, Ben-Shem E, Golan A and Levy T: The significance of normal pretreatment levels of CA125 $(<35 \mathrm{U} / \mathrm{mL})$ in epithelial ovarian carcinoma. Rambam Maimonides Med J 6: e0005, 2015.

38. Luo G, Xiao Z, Long J, Liu Z, Liu L, Liu C, Xu J, Ni Q and Yu X CA125 is superior to CA19-9 in predicting the resectability of pancreatic cancer. J Gastrointest Surg 17: 2092-2098, 2013.

39. Zhou P, Qu H, Shi H, Sun $\mathrm{G}$ and $\mathrm{He}$ Q: Predictive value of $\mathrm{CA} 125$ in peritoneal metastasis and prognosis of patients with gastric carcinoma. Zhonghua Wei Chang Wai Ke Za Zhi 17: 1027-1030, 2014 (In Chinese).

40. Hartwig W, Werner J, Jäger D, Debus J and Büchler MW: Improvement of surgical results for pancreatic cancer. Lancet Oncol 14: e476-e485, 2013

41. Eisenhauer EA, Therasse P, Bogaerts J, Schwartz LH, Sargent D, Ford R, Dancey J, Arbuck S, Gwyther S, Mooney M, et al: New response evaluation criteria in solid tumours: Revised RECIST guideline (version 1.1). Eur J Cancer 45: 228-247, 2009.

42. Simeone DM and Pandol SJ: The pancreas: Biology, diseases, and therapy. Gastroenterology 144: 1163-1165, 2013. 
43. Liu F, Du F and Chen X: Multiple tumor marker protein chip detection system in diagnosis of pancreatic cancer. World J Surg Oncol 12: 333, 2014

44. Rao TD, Tian H, Ma X, Yan X, Thapi S, Schultz N, Rosales N, Monette S, Wang A, Hyman DM, et al: Expression of the carboxy-terminal portion of MUC16/CA125 induces transformation and tumor invasion. PLoS One 10: e0126633, 2015.

45. Das S, Rachagani S, Torres-Gonzalez MP, Lakshmanan I, Majhi PD, Smith LM, Wagner KU and Batra SK: Carboxylterminal domain of MUC16 imparts tumorigenic and metastatic functions through nuclear translocation of JAK2 to pancreatic cancer cells. Oncotarget 6: 5772-5787, 2015.

46. Hoshino M, Kawashima H, Ogose A, Kudo N, Ariizumi T, Hotta T, Umezu H, Hatano H, Morita T, Nishio J, et al: Serum CA 125 expression as a tumor marker for diagnosis and monitoring the clinical course of epithelioid sarcoma. J Cancer Res Clin Oncol 136: 457-464, 2010.

47. Xu HX, Chen T, Wang WQ, Wu CT, Liu C, Long J, Xu J, Zhang YJ, Chen RH, Liu L, et al: Metabolic tumour burden assessed by ${ }^{18}$ F-FDG PET/CT associated with serum CA19-9 predicts pancreatic cancer outcome after resection. Eur J Nucl Med Mol Imaging 41: 1093-1102, 2014.

48. Luo G, Liu Z, Guo M, Jin K, Xiao Z, Liu L, Xu J, Zhang B, Liu C, Huang D, et al: (18)F-FDG PET/CT can be used to detect nonfunctioning pancreatic neuroendocrine tumors. Int J Oncol 45: 1531-1536, 2014.

49. Shi S, Ji S, Qin Y, Xu J, Zhang B, Xu W, Liu J, Long J, Liu C, Liu L, et al: Metabolic tumor burden is associated with major oncogenomic alterations and serum tumor markers in patients with resected pancreatic cancer. Cancer Lett 360: 227-233, 2015

50. Xiang J, Liu L, Wang W, Xu H, Wu C, Xu J, Liu C, Long J, Ni Q and Yu X: Metabolic tumor burden: A new promising way to reach precise personalized therapy in PDAC. Cancer Lett 359: 165-168, 2015.

51. Mercadal L: Tumour markers in chronic kidney disease. Nephrol Ther 11: 122-124, 2015 (In French).

52. Ng WW, Tong KJ, Tam TN and Lee SD: Clinical values of CA19-9, CA125 and CEA in malignant obstructive jaundice. Zhonghua Yi Xue Za Zhi (Taipei) 55: 438-446, 1995.

53. Chen T, Zhang MG, Xu HX, Wang WQ, Liu L and Yu XJ: Preoperative serum CA125 levels predict the prognosis in hyperbilirubinemia patients with resectable pancreatic ductal adenocarcinoma. Medicine (Baltimore) 94: e751, 2015.

54. Lai H, Jin Q, Lin Y, Mo X, Li B, He K and Chen J: Combined use of lysyl oxidase, carcino-embryonic antigen, and carbohydrate antigens improves the sensitivity of biomarkers in predicting lymph node metastasis and peritoneal metastasis in gastric cancer. Tumour Biol 35: 10547-10554, 2014.

55. Chanvorachote $\mathrm{P}$, Luanpitpong $\mathrm{S}$, Chunhacha $\mathrm{P}$, Promden $\mathrm{W}$ and Sriuranpong V: Expression of CA125 and cisplatin susceptibility of pleural effusion-derived human lung cancer cells from a Thai patient. Oncol Lett 4: 252-256, 2012.

56. Kawabe T, Hirano M, Mohri M, Sugimoto T, Nagata Y, Hisada M, Muto H, Unuma T, Momose T, Naka H, et al: CA125 in patients with pleural effusion - in comparison with ascites patients. Rinsho Byori 35: 905-909, 1987 (In Japanese).

57. Duraker N, Hot S, Polat Y, Höbek A, Gençler N and Urhan N: CEA, CA 19-9, and CA 125 in the differential diagnosis of benign and malignant pancreatic diseases with or without jaundice. J Surg Oncol 95: 142-147, 2007.

58. Parsons CM, Sutcliffe JL and Bold RJ: Preoperative evaluation of pancreatic adenocarcinoma. J Hepatobiliary Pancreat Surg 15: 429-435, 2008

59. Callery MP, Chang KJ, Fishman EK, Talamonti MS, William Traverso L and Linehan DC: Pretreatment assessment of resectable and borderline resectable pancreatic cancer: expert consensus statement. Ann Surg Oncol 16: 1727-1733, 2009.

60. Valls C, Andia E, Sanchez A, Fabregat J, Pozuelo O, Quintero JC Serrano T, Garcia-Borobia F and Jorba R: Dual-phase helical CT of pancreatic adenocarcinoma: assessment of resectability before surgery. AJR Am J Roentgenol 178: 821-826, 2002.

61. Maithel SK, Maloney S, Winston C, Gonen M, D'Angelica MI, Dematteo RP, Jarnagin WR, Brennan MF and Allen PJ: Preoperative CA 19-9 and the yield of staging laparoscopy in patients with radiographically resectable pancreatic adenocarcinoma. Ann Surg Oncol 15: 3512-3520, 2008.

62. Addeo P, Rosso E, Fuchshuber P, Oussoultzoglou E, De Blasi V, Simone G, Belletier C, Dufour P and Bachellier P: Resection of borderline resectable and locally advanced pancreatic adenocarcinomas after neoadjuvant chemotherapy. Oncology 89: 37-46, 2015.
63. Naik R and Barton DP: Neoadjuvant chemotherapy or primary surgery in advanced ovarian cancer. N Engl J Med 363: 2370-2371, author reply 2372, 2010.

64. Pross M, Wellner UF, Honselmann KC, Jung C, Deichmann S, Keck T and Bausch D: Neoadjuvant therapy in pancreatic cancer: Review article. JOP 16: 110-114, 2015.

65. Hidalgo M: Pancreatic cancer. N Engl J Med 362: 1605-1617, 2010.

66. Petrelli F, Coinu A, Borgonovo K, Cabiddu M, Ghilardi M, Lonati V, Aitini E and Barni S; Gruppo Italiano per lo Studio dei Carcinomi dell'Apparato Digerente (GISCAD): FOLFIRINOXbased neoadjuvant therapy in borderline resectable or unresectable pancreatic cancer: A meta-analytical review of published studies. Pancreas 44: 515-521, 2015.

67. Shimizu A, Hirono S, Tani M, Kawai M, Okada K, Miyazawa M, Kitahata Y,Nakamura Y,Noda T, Yokoyama S, et al: Coexpression of MUC16 and mesothelin is related to the invasion process in pancreatic ductal adenocarcinoma. Cancer Sci 103: 739-746, 2012.

68. Pelissier A, Bonneau C, Chéreau E, de La Motte Rouge T, Fourchotte V, Daraï E and Rouzier R: CA125 kinetic parameters predict optimal cytoreduction in patients with advanced epithelial ovarian cancer treated with neoadjuvant chemotherapy. Gynecol Oncol 135: 542-546, 2014

69. Mou W, Liu Z, Luo Y, Zou M, Ren C, Zhang C, Wen X, Wang Y and Tian Y: Development and cross-validation of prognostic models to assess the treatment effect of cisplatin/pemetrexed chemotherapy in lung adenocarcinoma patients. Med Oncol 31: 59, 2014.

70. Hwang GI, Yoo CH, Sohn BH, Shin JH, Park YL, Kim HD, Kim YS, Han WK and Pae WK: Predictive value of preoperative serum CEA, CA19-9 and CA125 levels for peritoneal metastasis in patients with gastric carcinoma. Cancer Res Treat 36: 178-181, 2004.

71. Pignata S, Cannella L, Leopardo D, Bruni GS, Facchini G and Pisano C: Follow-up with CA125 after primary therapy of advanced ovarian cancer: in favor of continuing to prescribe CA125 during follow-up. Ann Oncol 22 Suppl 8: viii40-viii44, 2011

72. Myriokefalitaki E, Vorgias G, Vlahos G and Rodolakis A: Prognostic value of preoperative Ca125 and Tag72 serum levels and their correlation to disease relapse and survival in endometrial cancer. Arch Gynecol Obstet 292: 647-654, 2015.

73. Sun Z and Zhang N: Clinical evaluation of CEA, CA19-9, CA72-4 and CA125 in gastric cancer patients with neoadjuvant chemotherapy. World J Surg Oncol 12: 397, 2014.

74. Katz MH, Varadhachary GR, Fleming JB, Wolff RA, Lee JE, Pisters PW, Vauthey JN, Abdalla EK, Sun CC, Wang H, et al: Serum CA 19-9 as a marker of resectability and survival in patients with potentially resectable pancreatic cancer treated with neoadjuvant chemoradiation. Ann Surg Oncol 17: 1794-1801, 2010.

75. Škrha P, Hořínek A, Anděl M and Škrha J: miRNA-192, miRNA-21 and miRNA-200: New pancreatic cancer markers in diabetic patients? Vnitr Lek 61: 351-354, 2015 (In Czech).

76. Körner M, Waser B, Strobel O, Büchler M and Reubi JC: Neurotensin receptors in pancreatic ductal carcinomas. EJNMMI Res 5: 17, 2015.

77. Zhang J, Zuo CJ, Jia NY, Wang JH, Hu SP, Yu ZF, Zheng Y, Zhang AY and Feng XY: Cross-modality PET/CT and contrast-enhanced CT imaging for pancreatic cancer. World J Gastroenterol 21: 2988-2996, 2015.

78. Okano K, Oshima M, Yamamoto N and Suzuki Y: PET imaging in the diagnosis of pancreatic cancer. Nihon Rinsho 73 (Suppl 3): 79-83, 2015 (In Japanese).

79. Wang $Z$ and Tian YP: Clinical value of serum tumor markers CA19-9, CA125 and CA72-4 in the diagnosis of pancreatic carcinoma. Mol Clin Oncol 2: 265-268, 2014.

80. Yang Y, Chen H, Wang D, Luo W, Zhu B and Zhang Z: Diagnosis of pancreatic carcinoma based on combined measurement of multiple serum tumor markers using artificial neural network analysis. Chin Med J (Engl) 127: 1891-1896, 2014.

81. Nolen BM, Brand RE, Prosser D, Velikokhatnaya L, Allen PJ, Zeh HJ, Grizzle WE, Huang Y, Lomakin A and Lokshin AE: Prediagnostic serum biomarkers as early detection tools for pancreatic cancer in a large prospective cohort study. PLoS One 9: e94928, 2014

82. Chang ST, Zahn JM, Horecka J, Kunz PL, Ford JM, Fisher GA, Le QT, Chang DT, Ji H and Koong AC: Identification of a biomarker panel using a multiplex proximity ligation assay improves accuracy of pancreatic cancer diagnosis. J Transl Med 7: 105, 2009. 